\title{
UTEROVAGINAL PROLAPSE WITH MULTIPLE VESICAL CALCULI: A RARE CASE REPORT
}

\author{
SAHA MR ${ }^{1}$, SAHA TK ${ }^{2}$, WAHAB MAKA ${ }^{3}$, HAQUE MR ${ }^{4}$
}

\begin{abstract}
Uterine prolase is a common gynaecological disease.It is usually associated with cystocele and or rectocele as well as enterocele. Recurrent urinary tract infections may occur in chronically unreduced cystocele leading to calculus formation,cystitis,pyelitis,pyelonephritis and renal failure.We report a case of a 70 years old multiparous lady with third degree uterovaginal prolapse for twenty years, presence of multiple vesical calculus in the cystocele was noted on $X$-ray pelvis while undergoing investigation. Suprapubic cystolithotomy followed by vaginal hysterectomy with pelvic floor repair was done. Multiple vesical calculus were removed. Postoperative course was uneventful and she was discharged on $10^{\text {th }}$ post-operative day. Patient is still on follow up with good urinary function and no recurrent UTI.
\end{abstract}

Key words: Hysterectomy,uterovaginal prolapse,vesical calculi.

J Dhaka Med Coll. 2016; 25(1): 77-79

\section{Introduction}

The association of giant vesical calculi and uterovaginal prolapse is uncommon entity. ${ }^{1,2}$ Prolapse is defined as protrusion of the pelvic organs into or out of the vaginal canal.Uterine prolapse occurs most commonly in multiparous due to result of childbirth injuries to the endopelvic fascia and lacerations of muscle especially the levator ani muscles and the perineal body in post-menopausal period due to oestrogen deficiency.Additional factors promoting uterine prolapse include obesity, asthma ,chronic bronchitis, bronchiectasis, chronic constipation, ascites, lifting heavy weights, subinvolution of the uterus, myohyperplasia of the uterus. There is often an accompanying cystocele and or rectocele as well as enterocele. ${ }^{3}$ Hydroureter and hydronephrosis occur due to downward movement of bladder along with uterine prolapse which involves the lower end of the ureters.In cases of acute irreducible pelvic organ prolapse or incarcerated procindentia, the possibility of bladder stones should be confirmed by X-ray pelvis including the prolapse mass. ${ }^{3,4}$ Impairment of renal function is generally limited to neglected cases.

\section{Case report}

A 70 year old multiparous postmenopausal lady status of 15 years, presented with mass coming out per vaginum for twenty years which was gradually increasing in size. She also had difficulty in passing urine for one year. She was para 4 with 2 living issues, all were home deliveries, the last one was 30 years ago. On examination she was malnourished, pale and had tender mass over both flank region, with no abnormality in other system. Per abdominally there was no mass. Pelvic examination revealed third degree irreducible uterovaginal prolapse with moderate rectocele and moderate cystocele. On palpation of cystocele there was crackling sensation. Bladder sounding showed that the entire bladder was below the level of urethra and filled with stones. No adnexal pathology was detected on rectal examination. The case was clinically diagnosed as third degree uterine prolapse with cystocele and multiple vesical calculi. She was non hypertensive and non diabetic.Her investigations showed haemoglobin $12 \mathrm{~g} /$ dl,blood urea $25 \mathrm{mg} / \mathrm{dl}$, serum creatinine 1.3 $\mathrm{mg} / \mathrm{dl}$, sodium $148 \mathrm{mEq} / 1$, chloride $102 \mathrm{mEq} /$ 1,blood sugar levels were within normal limits.

1. Dr. Mukti Rani Saha, Asst. Prof. (Gynae \& Obs), Mugda Medical College \& Hospital

2. Prof. Tapan Kumer Saha, Professor, Department of Surgery, Dhaka Medical College.

3. Dr. Md. Al Kamal Abdul Wahab, Asst. Prof. (Urology) Kurmitola General Hospital.

4. Dr. Md. Rajibul Haque, Registrar, Department of Surgery, DMCH, Dhaka

Correspondence : Dr. Mukti Rani Saha, Asst. Prof. (Gynae \& Obs), Mugda Medical College \& Hospital, Mobile No: - 01715-222508, Email: muktiroy75@gmail.com 
Urine examination showed plenty of WBCs and epithelial cells.Ultrasound pelvis reported bilateral hydronephrosis. Plain X-ray of the pelvis showed that the entire bladder was below the suprapubic arch and filled with calculi. Plain $\mathrm{X}$-ray of abdomen showed no calculi in kidney ureteric region. Case was taken for vaginal hysterectomy. After giving spinal anaesthesia, we push the bladder up then vesical calculi were removed through suprapubic cystolithotomy. The large calculi was about $6 \times$ $8 \mathrm{~cm}$. Bladder wall was closed with vicryl 2,0 round body. then vaginal hysterectomy with pelvic floor repair was done and transurethral Foley's catheter was inserted.postoperative period was uneventful. Catheter was removed after two weeks. Four weeks after discharge, she received a plain abdominal X-ray and abdominal sonography.no urolithiasis or hydronephrosis were found. Since then,the patient has regularly visited our outpatient department and now is completely well.

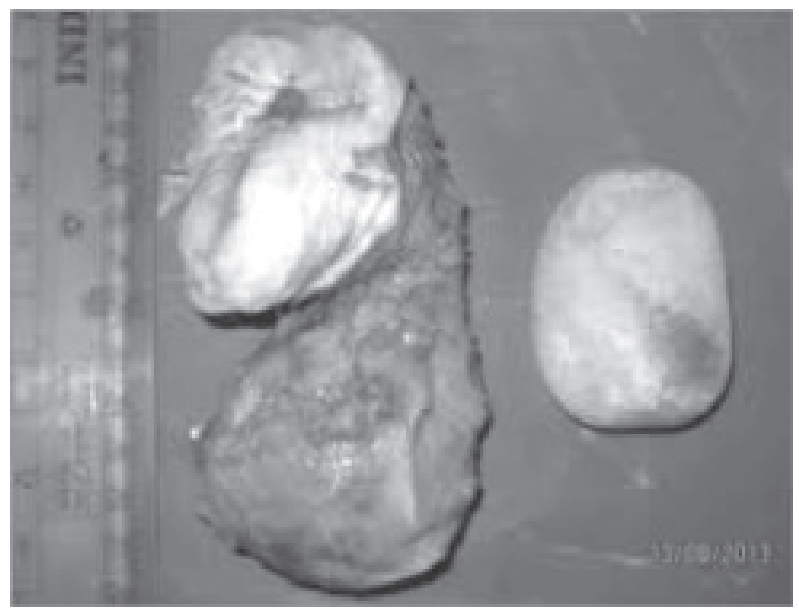

Fig-1: Showing the largest Stone measuring about $4 \times 5 \mathrm{~cm}$

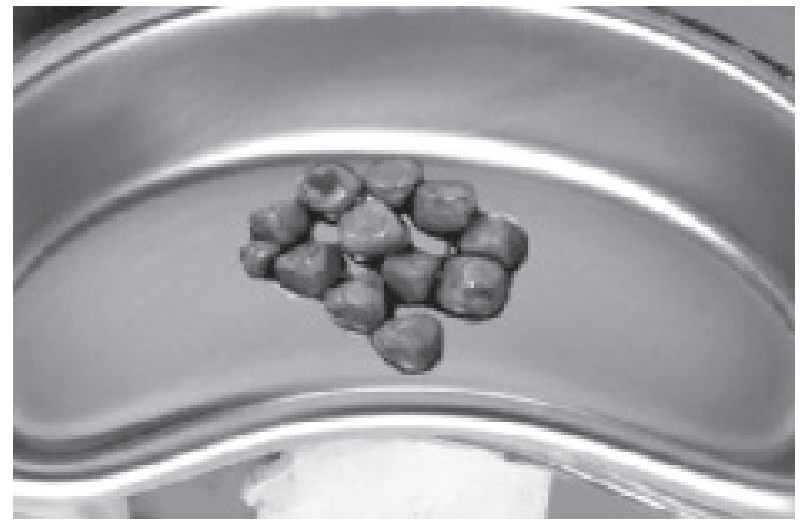

Fig-2: Showing Multiple Stones after removal

\section{Discussion}

An urinary bladder stone is usually defined as a giant calculus when its weighs $>100 \mathrm{~g}$. Urinary bladder calculi constitute $5 \%$ of all urolithiasis. ${ }^{4}$ The incidence of female urinary lithiasis is very low; 95\% of all bladder stones occur in men. The male-to-female ratio is approximately 3:1. ${ }^{5}$ Long- standing prolapse and bladder outlet obstruction, coupled with chronic infection are suspected to be the inciting factors. Cases of vesical calculus resulting in azotemia and retention of urine and obstructive uropathy have been reported ${ }^{5,6} \mathrm{Few}$ Cases of vesical calculi causing mechanical dystocia during labor, recurrent cystitis for over a decade and vesicovaginal fistula has been reported in literature. $\mathrm{w}^{-} \mathrm{y}$ the initial imaging study of choice is plain radiography of the kidneys, ureters and bladder (KUB) because it is the least expensive and easiest radiologic test to obtain. A radiograph of the pelvis, including the prolapsed tissues is warranted in the preoperative work up in patients with incarcerated procidentia.

With the widespread availability of ultrasonography, this relatively inexpensive and rapid modality can be more widely used to diagnose bladder calculus. The sonogram showing a classic hyperechoic object with posterior shadowing is effective in identifying both radiolucent and radio-opaque stones. Computed tomography (CT) scan is usually obtained for other reasons (e.g. abdominal pain, pelvic mass, suspected abscess) but may demonstrate bladder calculi when performed without intravenous contrast.

Magnetic resonance imaging (MRI) is an expensive imaging modality that yields poor resolution of calculi. It is not recommended in the evaluation of bladder calculi. Surgery by open technique has been the best recommended modality for large stones. ${ }^{9}$ Suprapubic percutaneous lithotripsy has complete stone clearance in adults though the procedure takes a long time; stone clearance is complete.

\section{Conclusion}

Uterine prolapse is a common gynecological disorder. A long standing prolapse, usually $3^{\text {rd }}$ 
degree prolapse, if untreated may cause renal complications like acute renal failure, uremia and bladder stone. Here we report a rare case of bladder stone caused by $2^{\text {nd }}$ degree uterine prolapse for which the patient required cystolithotomy and hysterectomy.

\section{References}

1. Singal R, Goyal S, Sekhon MS, Pandit S. A rare giant urinary bladder stone: Case Report. urotoday Int $\mathrm{J} 2010 ; 3(3)$

2. Johnson CG. giant calculus In The urinary bladder associated with complete uterine Prolapse; report of a case. Obstet Gynecol 1958;11(5): $579-80$

3. Siriwardana PN, Gunasekara M. Multiple vesical calculi in acCystocele: an uncommon complication of Procidentia. J Pelvic Med Surg 2008; 14(3): 207-8.

4. Dahiya P, Gupta A, Sangwan K. Multiple bladder calculi: a rare cause of Irreducible uterine
Prolapse. Arch Gynecol Obstet 2007; 275(5): 411-2.

5. Kang LM, Liu CH, Huang CI, Lee MG. Uterine Prolapse results In vesical Stones, ureteral stone, and acute renal failure: a case report. Journal of urology ROC 2000; 11(4):190-2.

6. Rege SA, Nunes QM, Dalvi AN. Giant vesical calculus. Bombay Hospital Journal 2001;43(4): 582-3

7. Ait Benkaddour Y, Aboulfalah A, Abbassi H. Bladder Stone: uncommon cause of mechanical Dystocia. Arch Gynecol Obstet 2006;274(5): 323-4

8. Lin WY, Wu CF, Shee JJ, Chen CS. a decade Of recurrent cystitis In a woman due to a giant vesical Calculus. Int Urogynecol J Pelvic Floor Dysfunct 2006; $17(6): 674-5$

9. Deshmukh SN, Maske AN, Deshpande AP, Shende SP. Vesicocutaneous fistula caused by giant vesical calculus. Indian J Surg 2011; $73(2): 152-4$ 